\title{
The Turbopause experiment: atmospheric stability and turbulent structure spanning the turbopause altitude
}

\author{
G. A. Lehmacher ${ }^{1}$, T. D. Scott ${ }^{1}$, M. F. Larsen ${ }^{1}$, S. G. Bilén ${ }^{2}$, C. L. Croskey ${ }^{2}$, J. D. Mitchell ${ }^{2}$, M. Rapp ${ }^{3}$, F.-J. Lübken ${ }^{3}$, \\ and R. L. Collins ${ }^{4}$ \\ ${ }^{1}$ Department of Physics \& Astronomy, Clemson University, Clemson, SC, USA \\ ${ }^{2}$ Department of Electrical Engineering, The Pennsylvania State University, University Park, PA, USA \\ ${ }^{3}$ Leibniz-Institute for Atmospheric Physics, Kühlungsborn, Germany \\ ${ }^{4}$ Geophysical Institute, University of Alaska, Fairbanks, AK, USA
}

Received: 18 May 2011 - Revised: 3 November 2011 - Accepted: 15 December 2011 - Published: 23 December 2011

\begin{abstract}
Very few sequences of high resolution wind and temperature measurements in the lower thermosphere are available in the literature, which makes it difficult to verify the simulation results of models that would provide better understanding of the complex dynamics of the region. To address this problem the Turbopause experiment used four rockets launched over a period of approximately two hours from Poker Flat Research Range, Alaska $\left(64^{\circ} \mathrm{N}, 147^{\circ} \mathrm{W}\right)$ on the night of 17-18 February 2009. All four rocket payloads released trimethyl aluminum trails for neutral wind and turbulence measurements, and two of the rockets carried ionization gauges and fixed-bias Langmuir probes measuring neutral and electron densities, small-scale fluctuations and neutral temperatures. Two lidars monitored temperature structure and sodium densities. The observations were made under quiet geomagnetic conditions and show persistence in the wind magnitudes and shears throughout the observing period while being modulated by inertia-gravity waves. High resolution temperature profiles show the winter polar mesosphere and lower thermosphere in a state of relatively low stability with several quasi-adiabatic layers between 74 and $103 \mathrm{~km}$. Temperature and wind data were combined to calculate Richardson number profiles. Evidence for turbulence comes from simultaneous observations of density fluctuations and downward transport of sodium in a mixed layer near $75 \mathrm{~km}$; the observation of turbulent fluctuations and energy dissipation from $87-90 \mathrm{~km}$; and fast and irregular trail expansion at $90-93 \mathrm{~km}$, and especially between 95 to $103 \mathrm{~km}$. The regions of turbulent trails agree well with regions of quasi-adiabatic temperature gradients. Above
\end{abstract}

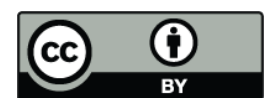

Correspondence to: G. A. Lehmacher (glehmac@clemson.edu)
$103 \mathrm{~km}$, trail diffusion was mainly laminar; however, unusual features and vortices in the trail diffusion were observed up to $118 \mathrm{~km}$ that have not been as prevalent or as clearly evident in earlier trail releases.

Keywords. Atmospheric composition and structure (Pressure, density, and temperature) - Meteorology and atmospheric dynamics (Turbulence; Waves and tides)

\section{Introduction}

The altitude range across the turbopause transition is one of the most dynamic regions in the Earth's atmosphere. The turbopause boundary is generally clearly evident in photographs of chemical tracer trails, which show a distinct transition from three-dimensional turbulent structure within the trails to a laminar flow over a vertical distance of a few hundred meters or less and is often located around $103 \mathrm{~km}$ (e.g., Blamont, 1963). We may call this altitude the visual turbopause. Detailed observations of chemical trails suggest that below this level the atmosphere consists of layers and globules with homogeneous and isotropic turbulence (Rees et al., 1972). But even above the turbopause, diffusion may not be strictly molecular. Layers of anomalous diffusion are observed, i.e., the expansion is faster than from molecular diffusion alone (e.g., Roper, 1996). Rees et al. (1972) suggested that larger scale gravity waves may provide conditions for quiet and turbulent layers and that small scale dynamics is thought to be anisotropic and indicative for viscous dissipation of smaller scale gravity waves. The altitude range between 100 and $110 \mathrm{~km}$ is known to be a region where large wind speeds are common, and the altitude immediately below the wind peak

Published by Copernicus Publications on behalf of the European Geosciences Union. 
is known to have large and variable wind shears that are either unstable or close to instability (e.g., Larsen, 2002).

The turbopause may also be defined as the altitude where the eddy diffusion coefficient is equal to the molecular diffusion coefficient, $K_{\mathrm{e}} \sim K_{\mathrm{m}}$. Profiles of $K_{\mathrm{e}}$ have been derived from mixing ratio profiles (e.g., Danilov et al., 1979; von Zahn et al., 1990), and the so-defined mixing turbopause is also called the homopause. Since $K_{\mathrm{e}}$ depends on eddy sizes and time scales of mixing, Lübken (1992) introduced a turbulent diffusion coefficient $K_{\mathrm{t}}=\operatorname{Ri}\left(\epsilon / N^{2}\right)$ based on measured energy dissipation rates, $\epsilon$. This relationship assumes stable flows, with Brunt-Vaisälä (buoyancy) frequency squared, $N^{2}>0$, and uses often an average gradient Richardson number $R i \sim 0.81$ based on Weinstock (1981). With $K_{\mathrm{m}} \sim \nu$, the kinematic viscosity, the turbopause criterion has also been expressed as $\epsilon \sim \nu N^{2}$ (Lübken, 1992). A similar expression has been used to determine the classical radar turbopause (e.g., Hall et al., 2008). An alternative wave turbopause was suggested by Offermann et al. $(2006,2007,2009)$ based on the steep increase in the variance of satellite temperature profiles near $95 \mathrm{~km}$. It appears that different type of measurements define their own turbopause. In addition, turbulence and turbopause height are variable in time and space and depend on background atmosphere, wave forcing and instability conditions. The region is of great interest, since gravity waves and tides grow to very large amplitudes, dissipate and deposit their momentum into the mean flow. This smallscale and nonlinear dynamics is important for the global circulation, and models must be able to parameterize sub-grid processes efficiently and accurately using appropriate eddy diffusion coefficients.

A number of techniques provide wind measurements that extend up to altitudes close to the turbopause boundary, including medium-frequency (MF) radar measurements, meteor radar measurements, and resonance lidar measurements. Measurements that span the turbopause range are difficult to obtain, however, especially if good height resolution is required. The chemical release technique is the only available option that provides direct measurements of the wind profiles with good accuracy and height resolution. In addition to providing wind measurements, the technique also provides information about the turbulent structure in the medium since this motion is directly visible as structure in the trails. The disadvantage of the technique is that multiple measurements are usually difficult to obtain since multiple rocket launches are required. There have been only a handful of experiments that have provided wind measurements of this type over an extended time interval of several hours or longer. The data described here represent one of the few sets of such measurements. The same can be said for high-resolution neutral density and temperature measurements, which are necessary to determine kinematic viscosity and buoyancy frequency. In addition, the spectral analysis of neutral density fluctuations by observing the inner (and outer) scales of isotropic turbulence is an established technique to measure energy dissi- pation rates (Lübken et al., 1993), which can also only be accomplished by in situ rocket measurements. Finally, the combination of the simultaneous wind and temperature measurements provides context for the turbulent structure observed in the trails.

The Turbopause experiment was a study of instability and turbulence across turbopause altitudes. Four rockets were launched during a two-hour period on 18 February 2009 from Poker Flat Research Range, Chatanika, Alaska. In Sect. 2 we describe the experiment and in Sect. 3 we present temperature and wind measurements, gravity waves, stability conditions, density fluctuations and energy dissipation rates. Different regions of instability and mixing are discussed in Sect. 4 based on the observed density fluctuations and the morphology of the chemical trails, including above the nominal turbopause. Section 5 summarizes our results. A second paper by Collins et al. (2011) discusses the simultaneous Rayleigh and sodium lidar observations during the night.

\section{Experiment}

\subsection{Rocket measurements}

The criteria for launching the four-rocket sequence included clear skies over the northern part of Alaska and significant wave structure in the sodium density, in particular on the top side of the sodium layer. Clear skies were required both for the lidar measurements and for the groundbased observations of the chemical trails. The conditions were satisfied during the night of 18 February 2009 and the rockets were launched at 09:59, 10:29, 10:59, and 11:49 UTC from Poker Flat Research Range, Chatanika, Alaska $\left(64.9^{\circ} \mathrm{N}, 147.8^{\circ} \mathrm{W}\right)$. The NASA mission numbers were 41.077, 41.078, 41.079, and 41.076, respectively. More details are given in Table 1. The apogee is determined from the GPS data for the instrumented payload on 41.078 and 41.079 , and the radar altitude for the other two launches. The flights were to follow the same nominal trajectory to obtain observations near the same location. Flight 41.079 deviated slightly to the west, but its path differed only by $\sim 5 \mathrm{~km}$ at $90 \mathrm{~km}$ altitude on upleg and by $\sim 17 \mathrm{~km}$ on downleg from the other trajectories. For each flight, the upleg and downleg crossing of $90 \mathrm{~km}$ altitude was separated horizontally by $\sim 90-100 \mathrm{~km}$.

All four payloads included an experiment for releasing chemoluminescent trails. Trimethyl aluminum (TMA) was released from the payload as puffed trails, separately on upleg and downleg for a total of eight trails. Releases started at $T+76 \mathrm{~s}$, with 24 puffs, $2 \mathrm{~s}$ long and in $4-\mathrm{s}$ intervals, until $T+170 \mathrm{~s}$. The downleg trail started at $T+220 \mathrm{~s}$, with 25 puffs. The trails were photographed from three sites in Alaska - Poker Flat, Fort Yukon $\left(66.6^{\circ} \mathrm{N}, 145.3^{\circ} \mathrm{W}\right)$ and Coldfoot $\left(67.3^{\circ} \mathrm{N}, 150.2^{\circ} \mathrm{W}\right)$ - by synchronized digital and film cameras every $20 \mathrm{~s}$ (Poker Flat every $15 \mathrm{~s}$ ). 
Table 1. Parameters for four sounding rockets launched on 18 February 2009 from Poker Flat, Alaska. Azimuth is measured clockwise from north.

\begin{tabular}{lrrrr}
\hline NASA \# & 41.076 & 41.078 & 41.079 & 41.077 \\
\hline Payload & TMA only & TMA+Instr. & TMA+Instr. & TMA only \\
Launch time, UTC & $09: 59$ & $10: 29$ & $10: 59$ & $11: 49$ \\
Apogee [s] & 183.6 & 178.5 & 181.8 & 183.6 \\
Apogee [km] & 128.5 & 121.1 & 126.1 & 127.2 \\
Azimuth [ $\left.{ }^{\circ}\right]$ & 0.6 & 0.0 & -6.4 & -0.3 \\
\hline
\end{tabular}

Triangulation based on images from site pairs was used to determine the position of each trail as a function of time and height. The procedure has been used extensively in past experiments since the 1950s (e.g., see the review by Larsen, 2002). A fit to the star field in each photograph is used to determine the azimuth and elevation for each segment of the trail in the photograph. The look angles determined in this way are used to obtain the altitudes and horizontal positions for corresponding trail segments, based on photographs from site pairs. Typical uncertainties in the velocities, which were determined at $1-\mathrm{km}$ altitude intervals, are $5 \mathrm{~m} \mathrm{~s}^{-1}$. Figure 1 shows all four upleg trails photographed from Ft. Yukon six minutes after each respective launch. Altitude markers are given for each trail. Three of the for uppermost markers are higher than the respective apogee. This is possible since the altitude of the uppermost part of the trails changes rapidly as the trail expands and rises. For a vertical velocity component of $10 \mathrm{~m} \mathrm{~s}^{-1}$, the change is $1800 \mathrm{~m}$ for a time $180 \mathrm{~s}$ after the release, when these photos were taken. Features in the trail that are immediately evident are the coherence in the overall structure in the trails over the two-hour period of the experiment. The directional and height shears produce the kinks in the trail that are evident in the images. The major features persist from one trail to the next, although the upper kink moves downward with time. There is also a transition from more turbulent structure in the lower part of the trail to less turbulent structure in the upper part of the trail. More details will be discussed in Sect. 4.

The payloads 41.078 and 41.079 included an instrumented daughter payload, which was separated on upleg at about $60 \mathrm{~km}$ altitude. The nosetip was equipped with a small hemispherical fixed-bias Langmuir probe to collect negative charge (e.g., Croskey et al., 2006) and the aft section was equipped with the combined neutral and electron sensor (CONE), a spherical hot-filament ionization gauge surrounded with a spherical-grid fixed-bias electron probe (Giebeler et al., 1993). Profiles of electron (and negative ion) current were obtained on upleg and downleg, but profiles of neutral density were measured on downleg only when the CONE instrument was in ram flow. The ion currents measured by CONE were filtered to remove roll and coning modulations, converted to neutral densities using vacuum calibration data, corrected for aerodynamic flow enhance- ment (Rapp et al., 2001) and integrated to yield temperature profiles. The start temperature was chosen from the MSIS model at 112 and $115 \mathrm{~km}$, respectively (Picone et al., 2002). About $10 \mathrm{~km}$ below the start altitude, we estimate the total error of the temperature as $\sim 3 \mathrm{~K}$ (Rapp et al., 2001). All probe electrometer data were sampled and transmitted as DC data and, in addition, as AC data after on-board high-pass filtering to reduce the roll modulation and to provide further amplification. All data streams were sampled at $5000 \mathrm{~Hz}$ $\left(0.2 \mathrm{~m}\right.$ resolution at $\left.1000 \mathrm{~m} \mathrm{~s}^{-1}\right)$ to resolve small-scale density fluctuations and, where possible, to determine the turbulent inner scale. The relationship to the energy dissipation rate $\epsilon$ is based on the 1-D Kolmogorov (K41) spectrum with slope $-5 / 3$ and microscale $\eta=\left(v^{3} / \epsilon\right)^{1 / 4}$ with the inner scale given as $l_{0}=9.9 \eta$ using Heisenberg's description of the viscous subrange (Lübken et al., 1993). The kinematic viscosity $v=\mu / \rho$ is calculated using the measured neutral densities. It should be kept in mind that for fixed $\epsilon$ the inner scale grows as $\rho^{-3 / 4}$, i.e., almost inversely with density. For a relatively large value $\epsilon=100 \mathrm{~mW} \mathrm{~kg}^{-1}$, the inner scale is about 4,10 , $40,100,400 \mathrm{~m}$ at $70,80,90,100,110 \mathrm{~km}$ altitude, respectively.

\subsection{Ground-based measurements and launch conditions}

The resonance lidar at Poker Flat Research Range provided measurements of the mesospheric sodium profiles from 70 to $120 \mathrm{~km}$ with $15 \mathrm{~min}$ integration (Collins and Smith, 2004). Overturning of sodium density surfaces has been observed occasionally throughout the layer and suggests the presence of instability and turbulence (see also Larsen et al., 2004). In particular, we were monitoring the topside of the sodium layer near $100 \mathrm{~km}$ for signs of wave modulation and expansion, which triggered the rocket salvo. The layer exhibited also a downward expansion during the time of the rocket measurements (Collins et al., 2011), which coincided with a turbulent mixing layer between 74 and $78 \mathrm{~km}$ discussed below. The Rayleigh lidar at Poker Flat Research Range provided density and temperature profiles from 40 to near $80 \mathrm{~km}$ with minimum integration of two hours (Thurairajah et al., 2010). The sequence of temperature profiles throughout the night showed evidence of wave modulation in the upper stratosphere and mesosphere with a period of about $4 \mathrm{~h}$. 


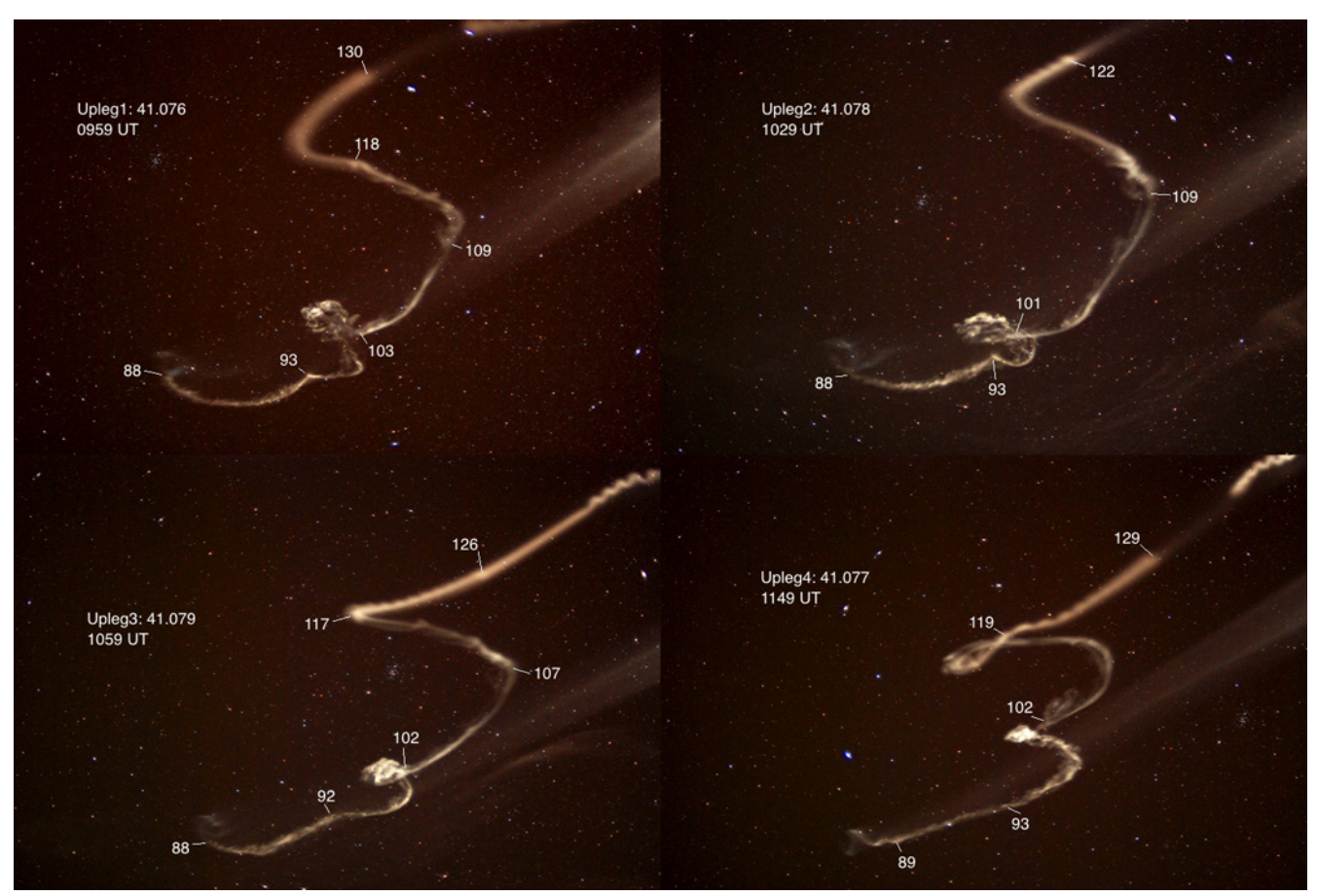

Fig. 1. Upleg trails from the four launches photographed six minutes after launch. Altitudes are marked in kilometers.

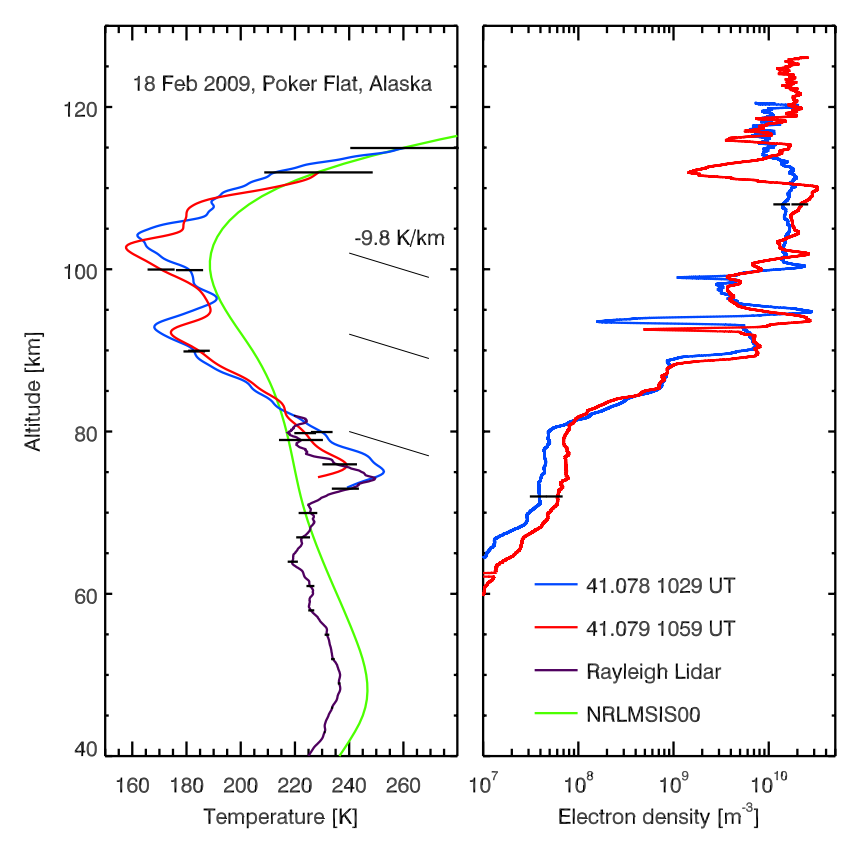

Fig. 2. Temperature profiles obtained by CONE instruments and Rayleigh lidar (left); electron density profiles obtained by nosetip probes and normalized in the E-region using incoherent scatter radar (right).

The 450-MHz Poker Flat Incoherent Scatter Radar (PFISR) collected data during the launch period (Nicolls and Heinselman, 2007). It was operated with interleaved long and short coded pulses for E- and F-region incoherent scatter and used five different beams. The ionospheric returns were very weak during the launch night, with E-region electron densities near $2 \times 10^{10} \mathrm{~m}^{-3}$, just five times the signal threshold for 15-min integrations. However, the data were helpful in calibrating the relative electron density profiles from the DC Langmuir probes.

The geomagnetic activity conditions prior to and during the launches were extremely quiet. The planetary Kp index was zero for 18h from 00:00 until 21:00 UTC. The auroral activity was monitored by several all-sky cameras across Alaska and a 4-channel meridional scanning photometer at Poker Flat. There was no indication of any significant auroral forcing during the observations.

\section{Results}

\subsection{Temperatures and electron densities}

The temperature profiles obtained by the CONE ionization gauges on flights 41.078 and 41.079 are shown in Fig. 2 (left panel). Since the flights took place only $30 \mathrm{~min}$ apart and closely in space, the profiles resemble each other strongly. The observed temperatures were colder than the corresponding MSIS model profile with a pronounced double mesopause structure. Temperature minima of $160 \mathrm{~K}$ and $170 \mathrm{~K}$ were found near $103 \mathrm{~km}$ and $93 \mathrm{~km}$, respectively. The lower thermosphere between 103 and $110 \mathrm{~km}$ contains regions of lower stability and some smaller fluctuations at 


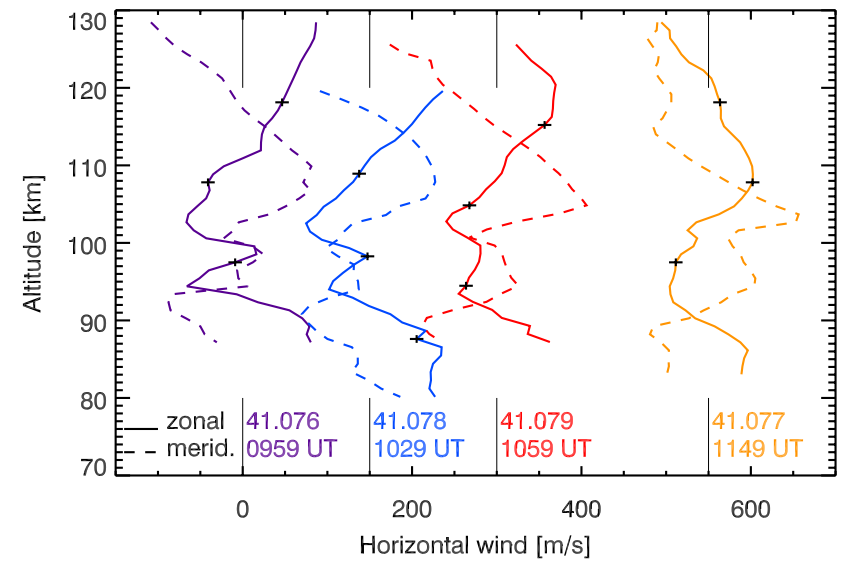

Fig. 3. Zonal and meridional wind profiles calculated from the four upleg TMA releases. Profiles are shifted horizontally relative to the first profile.

1-2 km scales, especially for flight 41.078 (see also Fig. 5). Between 95 and $103 \mathrm{~km}$, the temperature gradient is nearly adiabatic, suggesting a potential for instability. The same is true of the deep layer between 75 and $92 \mathrm{~km}$, which has an average temperature gradient of $-4.5 \mathrm{~K} \mathrm{~km}^{-1}$, and several regions with nearly adiabatic temperature gradients. Between 92 and $105 \mathrm{~km}$, the profile for 41.079 appears shifted downward by about $2 \mathrm{~km}$ compared to the earlier flight 41.078 indicating upward propagation of gravity waves. The downward phase propagation is also observed in the wind profiles (see below). Typical error bars are indicated for the start temperature and for some levels below.

From 40 to $82 \mathrm{~km}$, we add a temperature profile from the Rayleigh lidar. Data were integrated for a two-hour period centered at 10:30 UTC, and the start temperature was chosen to match the rocket data at $82 \mathrm{~km}$. Error bars are largest near the top due to lower photon counts. The lidar profile shows a pronounced mesospheric inversion layer at $72-74 \mathrm{~km}$ and an almost adiabatic layer at $74-78 \mathrm{~km}$. The two rocket profiles show a similar behavior below $80 \mathrm{~km}$, but the uncertainty is larger, since the payload attitude changes during reentry. Below $65 \mathrm{~km}$ the upper stratosphere and lower mesosphere are cooler than MSIS, which is consistent with the cooling response after the stratospheric warming at the end of January (Manney et al., 2009).

Profiles of electron density obtained by the nosetip probes on upleg are also shown in Fig. 2 (right panel). The density values were normalized using E-region electron densities from the PFISR radar. The profiles still differ below $80 \mathrm{~km}$, probably due to differences in angle-of-attack $\left(20^{\circ}\right.$ and $40^{\circ}$ for 41.079 and 41.078 , respectively, at $80 \mathrm{~km}$ on upleg) affecting the effective cross-section for charge collection, which includes negative ions. We estimate the combined errors for normalization and charge collection effects to be $10 \%$ of the densities. The nighttime electron density

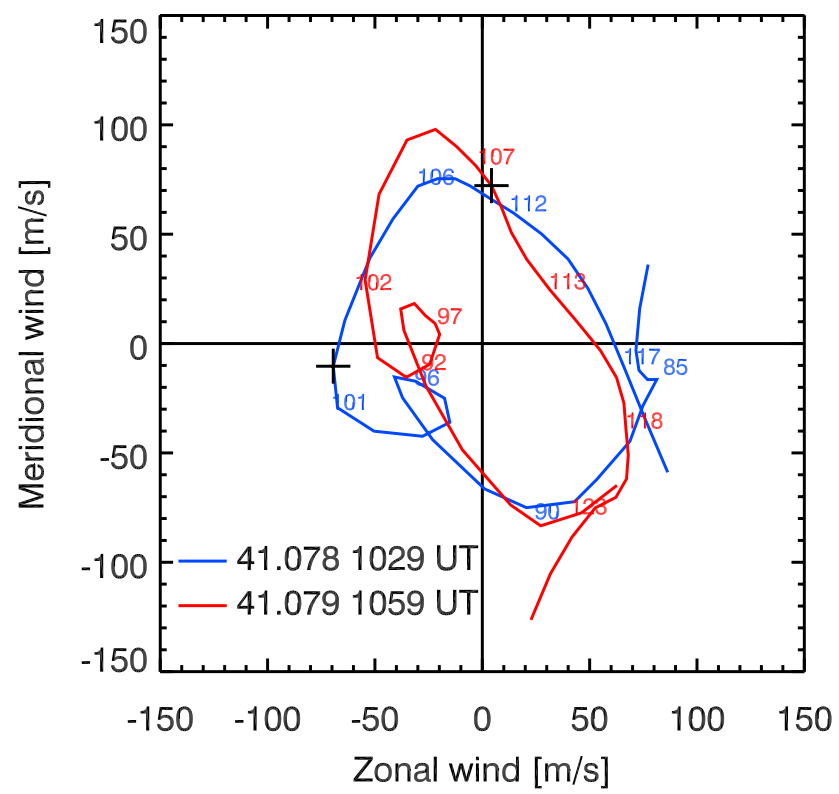

Fig. 4. Hodographs for flights 41.078 and 41.079. The numbers indicate altitudes in $\mathrm{km}$.

profiles demonstrate the quiet conditions with E-region values not exceeding $2 \times 10^{10} \mathrm{~m}^{-3}$. Characteristic features in the D region are steep gradients and layers of nearly constant electron density. The lower E-region contains also two weak and narrow sporadic layers near 94 and $100 \mathrm{~km}$ above unusual electron biteout regions, in particular for the lower layer. The lower sporadic layer shows similar downward progression as seen in the temperature profiles.

\subsection{Winds and gravity waves}

Figure 3 shows the sequence of zonal and meridional wind profiles from all four upleg TMA releases. The wind profiles show considerable consistency in the larger-scale structure over the two-hour period of the observations, although there is variability in the small-scale structure. We have indicated typical error bars for the vertical height $(0.5 \mathrm{~km})$ and horizontal wind components $\left(8 \mathrm{~m} \mathrm{~s}^{-1}\right)$ from the triangulations. There have only been a handful of experiments with multiple rocket wind measurements over intervals of several hours or more. A notable example was the launch from Barbados of six rockets on the night of 17-18 November 1965, over a period of nine hours, as described by Larsen and Fesen (2009). Another was a series of three rocket launches from Wallops Island, Virginia, over a four hour period on the night of 29-30 June 2003 (Bishop et al., 2005). These experiments showed that the large-amplitude wind features and associated shears in the lower thermosphere persisted over time scales of many hours, similar to what was observed in this experiment. 
Table 2. Approximate gravity wave parameters from hodograph analysis of wind components.

\begin{tabular}{lrr}
\hline Gravity wave & 1 & 2 \\
\hline Period [h] & 12 & 8 \\
Vertical wavelength [km] & 30 & 10 \\
Horizontal wavelength, semimajor axis [km] & 10000 & 1200 \\
Horizontal wind amplitude, semimajor axis $\left[\mathrm{m} \mathrm{s}^{-1}\right]$ & 60 & 40 \\
Horizontal propagation direction & southeast & southeast \\
\hline
\end{tabular}

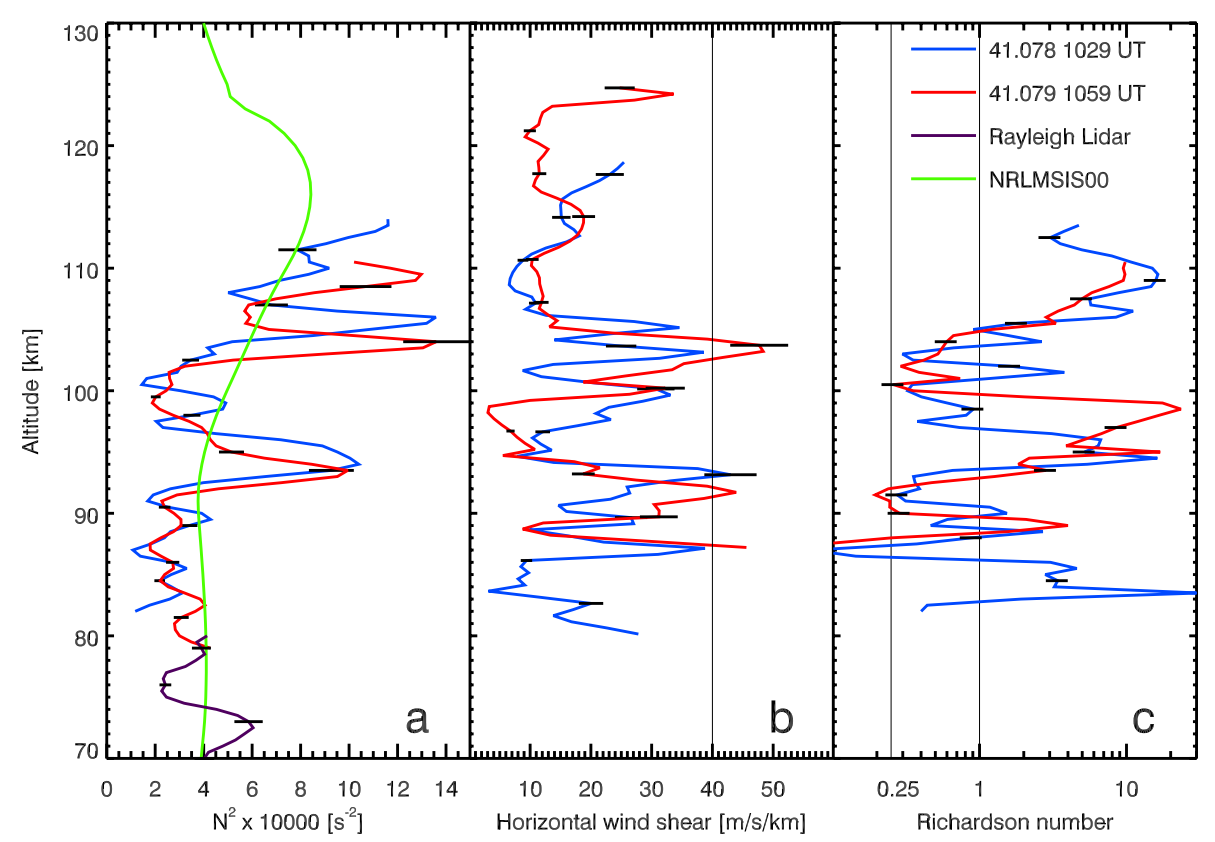

Fig. 5. (a) Brunt-Vaisälä frequency squared calculated from rocket and lidar temperatures, (b) wind shear from TMA winds, (c) Richardson number where observations overlap.

There is obvious downward progression in the altitudes of the wind maxima over the period. This can be best seen in the meridional component. For example, the broad northward maximum near $110 \mathrm{~km}$ for 41.076 moved downward and developed into a sharp maximum near $104 \mathrm{~km}$ for 41.077 . Similarly, the southward peak near $93 \mathrm{~km}$ shifted downward to $89 \mathrm{~km}$ at the end of the sequence. The downward progression suggests upward propagating gravity waves, which can also be recognized in the hodograph projection of the wind components, shown for flights 41.078 and 41.079 in Fig. 4. The downward phase progression is less obvious for the zonal component; however, this is likely due to the superposition of several waves with different phases (MacLeod and Vincent, 1985). Indeed, we can identify two inertia-gravity waves with different wavelengths and phases (see next paragraph). Errors for the two wind components are marked as crosses. The same error bar, $8 \mathrm{~m} \mathrm{~s}^{-1}$, is applied to both components and all altitudes.

For both flights, the wind vector describes approximately a closed ellipse, clockwise with increasing altitude, and with an additional smaller scale clockwise rotation around $97 \mathrm{~km}$. This shape may be approximated by the superposition of two inertia-gravity waves shifted by a background flow. A full rotation of the wind vector corresponds to the vertical wavelength, while the ratio between the semi-major and semiminor axes provides an estimate of the intrinsic period. By matching two monochromatic waves we find a $\sim 12$-h wave with $\sim 30 \mathrm{~km}$ vertical wavelength (possibly a semidiurnal tidal mode) and an $\sim 8$-h wave of $\sim 10 \mathrm{~km}$ vertical wavelength both propagating upward as indicated by the clockwise rotation of the wind vector. A similar result is obtained by empirical mode decomposition (EMD) of the individual wind profiles, but the wavelengths are found to change slightly with altitude. More wave parameters are given in Table 2 . The background wind components are close to zero, as can also be seen from the fact that the elliptical hodograph is centered at the origin. The waves propagate horizontally in direction of the semi-major axis, here in southeast direction. An exponential amplitude growth with height is not observed in this layer. In fact, EMD analysis shows the $10-\mathrm{km}$ wave 
being strongly damped near $110-112 \mathrm{~km}$. Our wave interpretation is further supported by the fact that the large scale temperature structure between 90 and $110 \mathrm{~km}$, notably the temperature minima near 92 and $103 \mathrm{~km}$, are roughly consistent with the polarization relations for wind and temperature amplitudes. The hodographs also illustrate nicely the small total wind speeds between 92 and $99 \mathrm{~km}$, which are consistent with the slow separation and knot-like appearance of the trail in this region Fig. 1.

Vertical winds were estimated near the top and the bottom of the trails, at features that could be tracked unambiguously. Results and comparisons with other vertical wind observations are discussed in Sect. 4.

\subsection{Stability}

From the temperature and wind profiles, we derive parameters of atmospheric stability, which are shown in Fig. 5: the buoyancy frequency squared $N^{2}$, the magnitude of the horizontal wind shear $|d \boldsymbol{u} / d z|=\sqrt{(\partial u / \partial z)^{2}+(\partial v / \partial z)^{2}}$, and the Richardson number $R i=N^{2} /|d \boldsymbol{u} / d z|^{2}$. Several error bars are shown which were calculated by combining the relative temperature and wind errors. The layers between $74-92 \mathrm{~km}$ and $97-103 \mathrm{~km}$ are close to adiabatic $\left(N^{2} \sim 0\right)$, while in between and above high static stability is observed. Notice also a narrow region of lower stability in the turbopause region between 105 and $108 \mathrm{~km}$. In general, the regions of small buoyancy frequency should be more prone to instability and turbulence. On the other hand, in these regions vertical adiabatic excursions of air parcels will result only in small neutral density perturbations.

The wind shear profiles are shown for the same two flights. They are highly structured; nevertheless, there is also considerable consistency. The largest wind shears are found in three regions: around $87-88 \mathrm{~km}, 92-94 \mathrm{~km}$ and $102-104 \mathrm{~km}$. In all three regions the wind shear magnitude exceeds $40 \mathrm{~m} \mathrm{~s}^{-1}$ per $\mathrm{km}$. Notice that the regions of large wind shear coincide approximately with the region of large static stability, which are consistent with the observed large scale gravity wave motion.

For calculating the Richardson number, we combine buoyancy frequencies and wind shears, but only where the data overlap. There have been very few previous experiments that have obtained quasi-simultaneous high-resolution wind measurements and high-resolution temperature measurements above $100 \mathrm{~km}$, and this is the first time that results from the CONE instrument and the chemical release technique are combined. Since we merge wind data from upleg with temperature data from downleg, it is mentioned again that the horizontal distance between the measurements was $\sim 90 \mathrm{~km}$, which is small compared to the horizontal wavelength of the long-period waves dominating the overall structure. Figure 4 indicates the lowest value $R i \sim 0.10$ near $87 \mathrm{~km}$ for both flights, and other regions having low values between 0.25 and 1.0 are near 90-94 km, and 97-106 km. In addition, horizontal gradients will also contribute to flow instability and grav- ity waves may become unstable for $R i>0.25$ (e.g., Achatz, 2007).

\subsection{Density fluctuations}

The neutral density fluctuations serve as passive tracers of turbulence, but electron fluctuations can be used only where the motion of the electrons is controlled by collisions with neutrals. This assumption can be verified if electron and neutral spectra resemble each other closely, which is typically the case in the D-region and lowest $\mathrm{E}$ region up to $\sim 92 \mathrm{~km}$. For our flights, good fluctuation data were obtained by the nosetip probe on upleg, since the angle of attack was smallest. For the CONE instrument, the downleg measurements occurred at large angles of attack $\left(\sim 90^{\circ}\right.$ near $100 \mathrm{~km}$ ), and the measurements were strongly modulated by roll motion $(4.8 \mathrm{~Hz})$ and coning $(0.45 \mathrm{~Hz})$ of the payload. As already mentioned, upleg and downleg measurements took place about $90 \mathrm{~km}$ apart, so the fluctuations on upleg and downleg represent independent samples of turbulence, but also illustrate the horizontal extent of the turbulent layer.

Figure 6 shows spectrograms of relative neutral fluctuations on downleg and electron fluctuations on upleg for flight 41.078. We used an 8192-point FFT (1.6s) to highlight relative large scales, $l \sim v_{\mathrm{R}} / f$, where $v_{\mathrm{R}}$ is the rocket velocity and $f$ the frequency. A third-degree polynomial was subtracted to suppress the DC component. As mentioned earlier, we expect inner scales of $100 \mathrm{~m}$ or more at $100 \mathrm{~km}$ and $10 \mathrm{~m}$ or more at $80 \mathrm{~km}$. Typical inner scales, expressed as frequencies in the rocket time frame, are indicated as white lines for different values of $\epsilon$. We show here in the left panel the full DC data set showing strong components at the coning frequency, the roll frequency, and multiples thereof, as vertical stripes in the spectrogram. Atmospheric density fluctuations must extend beyond this pattern to be significant. While DC data are shown to emphasize the large scale fluctuations, the high-pass filtered AC data offer a better signal-to-noise ratio for small scale fluctuations beyond $10 \mathrm{~Hz}$ and were used to fit the inner scale. The neutral data for 41.078 (left) exhibit two significant layers with the smallest fluctuations near 75$80 \mathrm{~km}$ and $89-92 \mathrm{~km}$. Some of these fluctuation spectra are characteristic for Kolmogorov (K41) turbulence (spectral in$\operatorname{dex} k^{-5 / 3}$ ) and the inner scale can be determined. Results for energy dissipation rates are discussed below. Fluctuations above $95 \mathrm{~km}$ are of the order of $500 \mathrm{~m}(2 \mathrm{~Hz})$. Flight 41.079 (not shown) has a similar spectrogram, but the fluctuation layers near 75 and $90 \mathrm{~km}$ were less distinct.

The electron density fluctuations are another set of observations, close in space and time. The right panel of Fig. 6 shows the fluctuations for flight 41.078. The small angle-ofattack causes much less coning and roll modulation relative to the total collected. The modulation near $5 \mathrm{~Hz}$ is mostly present in the D-region below $80 \mathrm{~km}$ and near apogee, when the angle-of-attack becomes larger, as can be seen in Fig. 6 . Obviously, the wide fluctuation layer around $75 \mathrm{~km}$ is present 

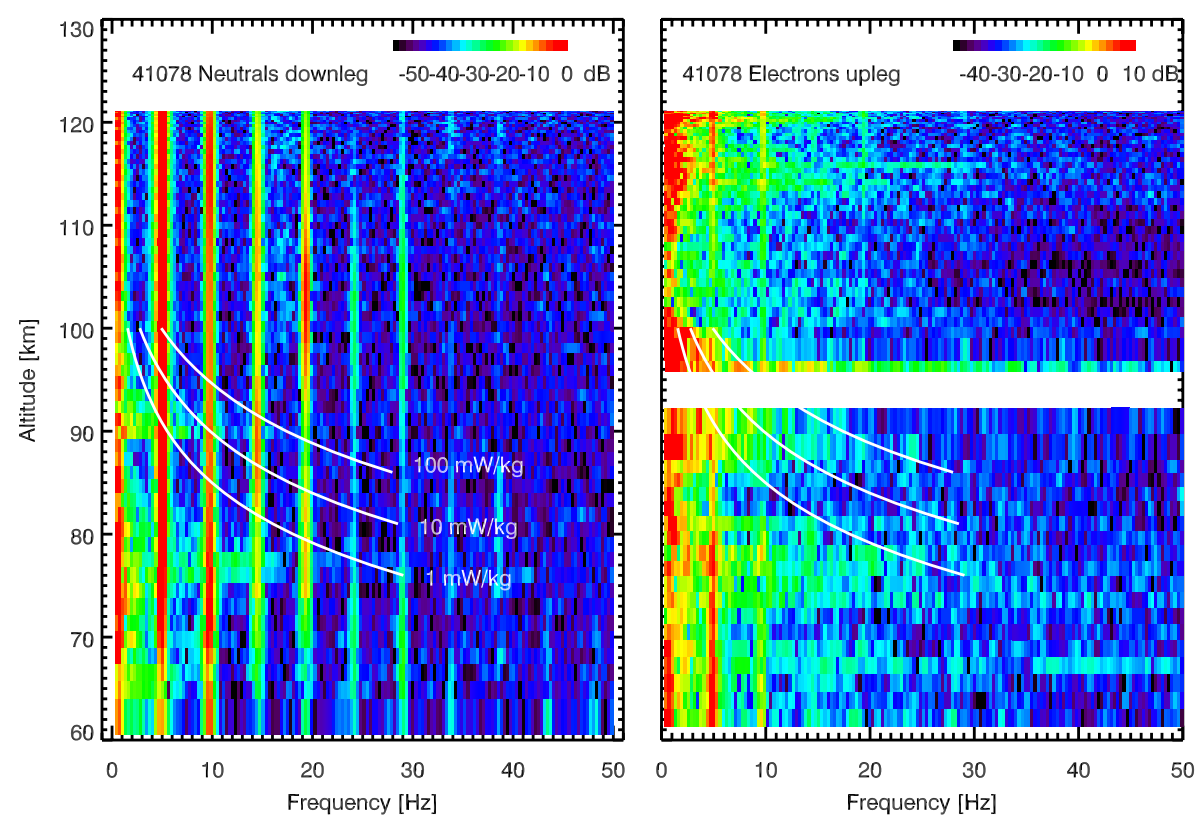

Fig. 6. Left: spectrogram of neutral density fluctuations for flight 41.078 on downleg, Right: same for nosetip probe electron fluctuations on upleg. The white curves are estimates where the fluctuation level drops off based on the inner scale of turbulence, payload velocity, and typical energy dissipation rates.

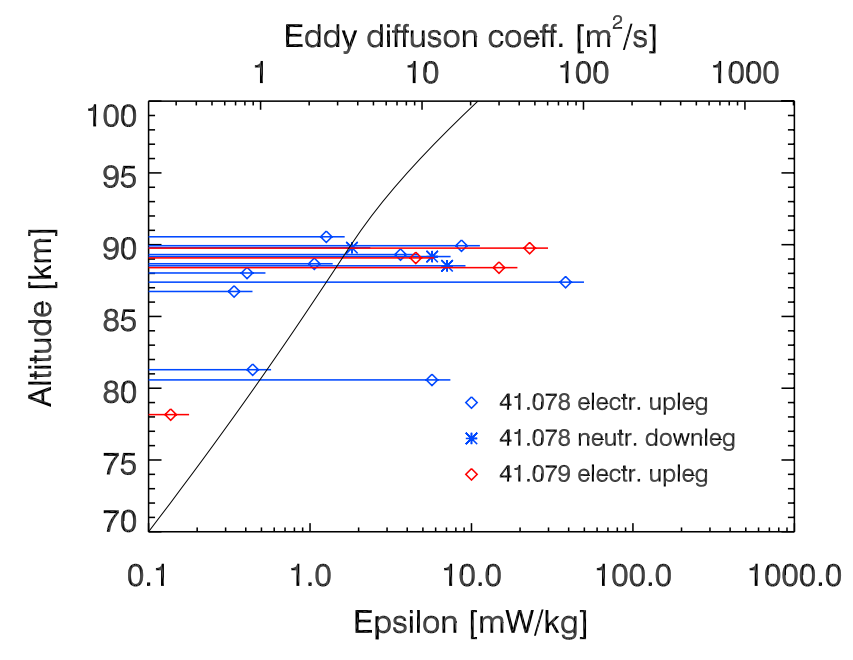

Fig. 7. Turbulent energy dissipation rates derived from the observation of the inner scale in the fluctuation spectra. The thin line indicates $\epsilon_{\min } \sim \nu N^{2}$, a threshold for significant levels of turbulence.

(strongest fluctuations between 73 and $81 \mathrm{~km}$ ), as well as enhanced fluctuations around $90 \mathrm{~km}$. Both layers with fluctuations are in regions with almost constant electron density and nearly adiabatic lapse rate (Fig. 2). Between 92 and $102 \mathrm{~km}$, the electron density profile was highly structured by sporadic E-layers; therefore, some step function-like features dominate the Fourier spectra and are excluded from the display. Just below $100 \mathrm{~km}$, there are strong fluctuations with scale sizes of $200 \mathrm{~m}$ and more. The scale sizes are compatible with neutral turbulence, but the spectra do not show a clear inner scale. Above $110 \mathrm{~km}$, fluctuations extend to relatively high frequencies, probably due to plasma instabilities, and some are associated with the strong electron density gradients (Fig. 2). The electron spectra for 41.079 are similar (not shown), with clear indications of neutral turbulence between 88 and $90 \mathrm{~km}$. In summary, the electron spectra confirm that electrons are useful tracers for turbulence up to $90-95 \mathrm{~km}$ altitude. They complement neutral fluctuation measurements, especially in regions with electron density gradients, and in adiabatic layers where neutral fluctuations are small.

\subsection{Energy dissipation rates}

In Fig. 7 we show values for turbulence energy dissipation rates obtained from spectral analysis of the CONE neutral density fluctuations on downleg and the nosetip electron density fluctuations on upleg. The extension beyond the symbols indicates the uncertainty of typically $30 \%$. The smallest levels of turbulence possible are estimated from $\epsilon_{\min } \sim \nu N^{2}$ and shown as a thin line. Data points near or below this threshold should be considered not significant. The top abscissa is labeled with turbulent diffusion coefficients using $K_{\mathrm{t}} \sim 0.81 \epsilon / N^{2}$ with $N^{2}=4 \times 10^{-4} \mathrm{~s}^{-2}$. As already suggested by studying the spectrograms, we can identify two turbulence regions. The upper region between 86 and $90 \mathrm{~km}$ has values range between $1.0( \pm 0.5)$ and $30( \pm 10) \mathrm{mW} \mathrm{kg}^{-1}$, the errors are estimated based on the quality of the spectral fits. The lower layer between 75 and $81 \mathrm{~km}$ is only represented 
by a single value of $6 \mathrm{~mW} \mathrm{~kg}^{-1}$ near $80.5 \mathrm{~km}$. While fluctuations are clearly present for adjacent altitudes, the power spectra do not allow fitting a turbulent spectrum.

\section{Discussion}

\subsection{Mixed layer at $75 \mathrm{~km}$}

The first layer of small scale fluctuations and turbulence was found between 74 and $78 \mathrm{~km}$. It was located just above a mesospheric inversion layer from 72 to $74 \mathrm{~km}$, as observed by Rayleigh lidar. The inversion layer formed within the previous two hours and descended rather quickly through the rest of the night. It was probably created along the temperature maximum of a large-scale four-hour wave that was propagating upward from the stratosphere (Collins et al., 2011). During the time of the rocket measurements the sodium lidar observed transport of sodium down to $74 \mathrm{~km}$. The mixing was strongest $\sim 11: 00$ UTC and extended up to $80 \mathrm{~km}$. Collins et al. used the observed sodium scale height and time constant for sodium loss and derived an eddy diffusion coefficient of $1800 \mathrm{~m}^{2} \mathrm{~s}^{-1}$ and energy dissipation rate of $35 \mathrm{~mW} \mathrm{~kg}^{-1}$. These were upper limits without additional loss due to horizontal transport. Using typical wind speeds, values may be $2-3$ times smaller, $600 \mathrm{~m}^{2} \mathrm{~s}^{-1}$ and $12 \mathrm{~mW} \mathrm{~kg}^{-1}$. As already mentioned, the mixing region is characterized by a nearly adiabatic lapse rate and constant electron density profile surrounded by step-like boundaries (Fig. 2). Intense turbulence apparently created a volume of homogeneous potential temperature, sodium and plasma density. Lehmacher and Lübken (1995) described a similar event, at almost the same altitude and similar extent, but at mid-latitudes. In this event, turbulent energy dissipation rates of $10 \mathrm{~mW} \mathrm{~kg}^{-1}$ were observed within the mixed layer, which is compatible with the value derived from the sodium diffusion. It remains unclear why we did not observe similar levels of turbulence either in the electron or neutral data. We observe $5 \mathrm{~mW} \mathrm{~kg}^{-1}$ at $80 \mathrm{~km}$, but this is above the main mixing region. There is clear evidence for small scale fluctuations in the mixing layer, but the inner scale cannot be identified in the spectrum. This example demonstrates that the concept of eddy diffusion at large scales is not necessary compatible with dissipation at small scales.

\subsection{Mixed layer at $90 \mathrm{~km}$}

Next we discuss the fluctuation layer between 87 and $93 \mathrm{~km}$. Again it coincides with a region of very low stability $N^{2}$, with a region of slightly higher stability near $89-90 \mathrm{~km}$. The electron density has a steep gradient up to $89 \mathrm{~km}$, followed by a mixed layer, the lowest part of the E-region. Remember that observations of relative fluctuations are largest across a strong background gradient. (Conversely, if there is no background gradient, velocity fluctuations may be present, but cannot be observed as density fluctuations.) The largest electron fluctuations and turbulence dissipation rates are found near $87-88 \mathrm{~km}$, which may be associated with the lowest Richardson numbers (Figs. 5, 6). For 41.079 the maximum dissipation rates were found between 88 and $90 \mathrm{~km}$, and the wind shears were larger at $90 \mathrm{~km}$ for this flight. Above $90 \mathrm{~km}$, fluctuations are very small and no turbulence spectra can be identified.

We now compare the trail images (Fig. 1) with these findings. The region from 87 to $93 \mathrm{~km}$ is easily identified in the images, ending at a pronounced kink in the trail with low wind speed. The trail clearly increased in width and became more structured up to $93 \mathrm{~km}$, best seen for 41.078. From triangulation using Ft. Yukon and Coldfoot images we estimate that the width was $300 \mathrm{~m}$ at $88 \mathrm{~km}$ and $600 \mathrm{~m}$ at $92 \mathrm{~km}$ at $40 \mathrm{~s}$ after the release and remained fairly constant. Blamont and de Jager (1961), Rees et al. (1972), Roper (1996) and Bishop et al. (2004) used the expansion rates of chemical trails to calculate energy dissipations rates and molecular and turbulent diffusion coefficients. The high time resolution data from Rees et al. (1972) show also that only the first few seconds of trail expansion are determined by non-ambient behavior, i.e., the initial motion from the release process. Then the trail expands by molecular diffusion, and subsequently, inertialscale turbulence is identified by a faster $\left(r^{2} \propto t^{3}\right)$ increase of the trail diameter for a certain amount of time. We do not have sufficient detail for the beginning of the trail expansion, but using $300 \mathrm{~m}$ as initial width and $30 \mathrm{~s}$ as expansion time as typical values from Bishop et al. (2004), the resulting energy dissipation rates would be negligible near $88 \mathrm{~km}$, but unreasonably large $\left(1500 \mathrm{~mW} \mathrm{~kg}^{-1}\right)$ for the expansion from 300 to $600 \mathrm{~m}$. Even a growth from 500 to $600 \mathrm{~m}$ over $40 \mathrm{~s}$ yields $250 \mathrm{~mW} \mathrm{~kg}^{-1}$. In contrast, Rees et al. (1972) observed in this region onset times for turbulent expansion of 10-20 s at trail diameters of only $40-60 \mathrm{~m}$ leading to much smaller dissipation rates of $10-20 \mathrm{~mW} \mathrm{~kg}^{-1}$. This example shows that large, irregular trail expansion is observed in a region of low stability. Density fluctuations are small and may be suppressed, but are not indicative of high Reynolds number turbulence. The trail is too wide and irregular $40 \mathrm{~s}$ after release and likely already in the break-up phase as discussed by Rees et al. (1972); estimates for energy dissipation rates are too high.

The turbulent energy dissipation rates from the observed fluctuation spectra range from 1 to $30 \mathrm{~mW} \mathrm{~kg}^{-1}$ and are compatible with similar wintertime measurements by Lübken et al. (1993) and Lübken (1997), who observed an average winter maximum of $21.8 \mathrm{~mW} \mathrm{~kg}^{-1}$ at $91 \mathrm{~km}$. Our results seem typical for winter conditions, although there is a strong seasonal variation of turbulent dissipation at high latitudes. Lübken (1997) reports the maximum of the polar mesosphere summer average at $90 \mathrm{~km}$ and $183 \mathrm{~mW} \mathrm{~kg}^{-1}$. Individual values show large variations, and strong turbulence has also been observed at other latitudes. Lehmacher et al. (2006) report a single observation at low latitudes with $170 \mathrm{~mW} \mathrm{~kg}^{-1}$ 
between 92 and $95 \mathrm{~km}$ associated with a tidal inversion layer. Bishop et al. (2004) identified a turbulent layer near $87 \mathrm{~km}$ with $130 \mathrm{~mW} \mathrm{~kg}^{-1}$ derived from TMA trail observations at midlatitudes. This layer was part of a large convectively unstable region extending from 87 to $95 \mathrm{~km}$ and characterized by mixing of atomic oxygen (Hecht et al., 2004). While larger values may occur in the upper mesosphere, our values seem typical for high-latitude winter conditions.

\subsection{Turbulence from 95 to $103 \mathrm{~km}$}

The trail was narrower between 93 and $95 \mathrm{~km}$, coincident with a region of high stability (Figs. 1 and 5). Above $95 \mathrm{~km}$ we see indications of neutral and electron density fluctuations, but the scale sizes of a few $100 \mathrm{~m}$ are rather large, and an inertial range and inner scale could not be found. The region between 95 and $103 \mathrm{~km}$ was characterized by low stability and variable wind shear, again similar to the convective layer observed by Hecht et al. (2004). The Richardson number profiles are highly structured and values are much lower than unity throughout the region.

We observe that all eight TMA trails show significant turbulent behavior up to about $102-103 \mathrm{~km}$ (Fig. 1). Notice that above the complex loop structure the trail reemerges still with a clearly visible center line. We have marked this position on the images with an altitude marker $(101,102$ or $103 \mathrm{~km}$ ), which is the transition height from globular (Blamont and de Jager, 1961) to laminar expansion or visible turbopause. It varies only slightly in altitude over the two-hour period. Earlier images show how the trail develops dozens of individual cells, resembling convective clouds. The expansion rate analysis has not been completed yet, but preliminary results for the $93 \mathrm{~km}$ region presented above show that the analysis will yield values too large for the dissipation rate when the entire width of the trail is considered. An important result is the connection between the obviously turbulent behavior and the region of convective instability, which may not necessarily include high wind shear. The Richardson number is below one, mainly determined by the low Brunt-Vaisälä frequencies.

Based on an average of 12 rocket flights with neutral density fluctuation measurements at winter high latitudes, turbulence levels are low with $7.2-21.8 \mathrm{~mW} \mathrm{~kg}^{-1}$ between 80 and $100 \mathrm{~km}$ (Lübken, 1997). There is not a similar collection of energy dissipation rates based on chemical release data, and since the early work discussed in Rees et al. (1972), there has been only one new analysis by Bishop et al. (2004) for the TOMEX trail. Rees et al. (1972) analyzed in images taken in one-second intervals and derived dissipation rates from the onset time for turbulence and also from the slope of the steep, $t^{3}$ expansion phase. They report smaller values for the first method, $40-120 \mathrm{~mW} \mathrm{~kg}^{-1}$, as compared to $370 \mathrm{~mW} \mathrm{~kg}^{-1}$ as single value for the second method, and discuss the uncertainty inherent in the irregular, non-Gaussian shape of the trail. Bishop et al. (2004) estimated values of
340 and $840 \mathrm{~mW} \mathrm{~kg}^{-1}$, at 100 and $98 \mathrm{~km}$, respectively, derived from measuring the expansion rate. These values were associated with kilometer-scale irregularities in the trail and a large wind shear, while at the same time large-scale overturning was observed in the sodium layer interpreted as convective roll instability (Larsen et al., 2004). While our fluctuation measurements do not support large $\epsilon$ values, the observation of trail structure in combination with low convective stability is evidence for turbulence up to $103 \mathrm{~km}$ altitude.

\subsection{Anomalous diffusion from 103 to $118 \mathrm{~km}$}

The region between 103 and $110 \mathrm{~km}$ was characterized by a stable temperature gradient and large wind shear, capped by a region of less stability and very small wind shear. The trail is more laminar up to $109 \mathrm{~km}$ (41.078) and $107 \mathrm{~km}$ (41.079), which marks a region of higher stability as seen in the temperature profiles. Above this we find large scale irregularities. The trails appear mostly laminar, but exhibit developing plumes and vortices that change into wispy structures as the wind disperses the trail. The direct visual evidence of turbulent behavior above $103 \mathrm{~km}$ in these trails is unusual, compared to a large number of similar trails in earlier release experiments.

However, faster than molecular diffusion in this region has been observed before and discussed in earlier publications (Rees et al., 1972). The viscosity becomes so large that the classical inertial subrange of turbulence does not appear; therefore, the behavior is sometimes called anomalous diffusion (Rees et al., 1972). We use this term loosely to describe small-scale features in the tracer that deviate from uniform expansion due to molecular diffusion. Blamont and de Jager (1961) already suggested that turbulence below $103 \mathrm{~km}$ is isotropic, but above the nominal turbopause the small scale behavior is anisotropic due to the viscous dissipation of gravity waves. Rees et al. (1972) describe the region as $1-2 \mathrm{~km}$ thick stable and unstable layers based on wind profile observations. Roper (1996) interprets the variable expansion rate of a TMA trail between 102 and $107 \mathrm{~km}$ as sequence of laminar and turbulent layers. Anomalous diffusion occurred also in the trail near 105 and $110 \mathrm{~km}$ analyzed by Bishop et al. (2004). Strong layering in the lower thermosphere with stable and unstable regions has also been observed in high resolution temperature profiles (Philbrick et al., 1985; Hillert et al., 1994; Lehmacher et al., 2006). Our wind, temperature and trail observations confirm that the lower thermosphere is highly structured and shows clear deviations from laminar behavior. It is new in our experiment that we have repeated temperature measurements extending into the lower thermosphere and can directly compare stability, wind shear and trail behavior. The absence of neutral density fluctuations in the vertical profile may support the idea that the smallest scales in the lower thermosphere are highly stratified as has been suggested, e.g., by Rees et al. (1972). 


\subsection{Trail expansion above $118 \mathrm{~km}$ and vertical motions}

Above $118 \mathrm{~km}$ the trail expands very rapidly and smoothly due to molecular diffusion. Some sections of the trails show a wavy modulation, which may be the combined effect of puffing and wake interaction (Roper, 1996).

Vertical velocity estimates are more difficult to determine, since they require specific identifiable features that can be tracked from one image to the next. The top of a trail, for example, is a recognizable feature, but it is usually not a good indicator of the vertical atmospheric motion since the location of the top will be determined by the horizontal and vertical diffusion of the chemical tracer, in addition to the effects of vertical atmospheric motions. In this experiment, however, the apogee for the four rockets was relatively low, and the top of the trail occurred along the nearly horizontal section of the trajectory near apogee. The vertical movement of the top of each trail over the observation interval was used therefore to obtain vertical velocity estimates at those altitudes. The bottom of the trail was another feature that was tracked, but the results were less reliable.

The vertical velocity at the upper end of the trails near $130 \mathrm{~km}$ altitude ranged between $8-13 \mathrm{~m} \mathrm{~s}^{-1}$. MacLeod (1968), using a puffed TMA release in a launch from Puerto Rico, found vertical winds of approximately $10 \mathrm{~m} \mathrm{~s}^{-1}$ at those altitudes, although the vertical velocities were more than twice as large at altitudes between 100 and $110 \mathrm{~km}$ where the largest winds and shears occurred. Rees (1969) used a series of rocket-borne grenade clouds to obtain the vertical velocity altitude profiles at Woomera, Australia, for launches carried out in October and April. The results were similar in that case, with vertical velocities of approximately $10 \mathrm{~m} \mathrm{~s}^{-1}$ magnitude. There have been no directly comparable measurements from Poker Flat, although Wescott et al. (2006) presented vertical wind estimates obtained from a horizontal TMA trail deployed across a quiet auroral arc at altitudes $10-25 \mathrm{~km}$ higher than those presented here. Their vertical wind magnitudes were approximately twice as large as those found in our study. Ishii et al. (2001) studied vertical velocities from oxygen green line observations during auroral forcing. They reported upward and downward velocities of up to $30 \mathrm{~m} \mathrm{~s}^{-1}$ depending on the location of the auroral arc. The vertical winds may be variable in both time and space; however, the vertical transport associated with such winds, even in a root-mean-square sense, can have important consequences for the chemistry and dynamics of the region.

\section{Summary and conclusions}

The Turbopause experiment was carried out to better understand the nature of turbulence from the upper mesosphere to the lower thermosphere across the turbopause region. The four rocket flights allowed an analysis of the neutral winds from TMA chemical releases over a two-hour period and a comparison with temperature structure and neutral and electron density fluctuations from instrumented flights. The expansion of the trails exhibits laminar and turbulent behaviors in relationship to wind shears and temperature gradients. Background information on temperatures and sodium densities was provided by two lidars, and electron densities by incoherent scatter radar.

The four wind profiles and the two-hour duration allowed a rare look at the time evolution of the neutral winds. The results showed that strong winds and large shears are persistent features of the wind profiles over an extended time scale. Features of the wind profiles displayed a downward phase progression, consistent with the phase propagation for upward propagating waves, which could be further specified as inertia-gravity waves by analysis of the hodographs.

The temperature profile was rather unusual with strongly negative temperature gradients, including quasi-adiabatic regions, throughout the upper mesosphere from 74 to $103 \mathrm{~km}$. Several regions of instability, wave breaking and turbulence were identified in this region. Levels of the energy dissipation rate were consistent with other winter high latitude measurements (Lübken et al., 1993; Lübken, 1997). Rayleigh lidar and instrumented rockets show evidence for significant gravity wave activity from the stratosphere to the lower thermosphere during the launch night.

The TMA trails show significant turbulent structure between 95 and $103 \mathrm{~km}$ and below $93 \mathrm{~km}$. In these regions, they expand fast and break up into many irregular patches, while from 93 to $95 \mathrm{~km}$ and above $103 \mathrm{~km}$, the trails remain more laminar. These observations match well the observed temperature profiles; the trails are wide and highly structured where the temperature gradient is close to adiabatic. Layers of large wind shear are embedded in this large scale structure. A region characteristic of isotropic turbulence was observed only between 87 and $90 \mathrm{~km}$ coincident with the lowest Richardson numbers. Above $90 \mathrm{~km}$, density fluctuations were small and inertial range turbulence was not found.

Above the $103 \mathrm{~km}$ level which is typically the region for the transition to laminar trail development, unusual structures were observed up to $118 \mathrm{~km}$ where such features have not been prevalent or as clearly evident in earlier trail releases. In conclusion, the simultaneous observations show that over a two-hour period large-scale convectively unstable regions played a major role in generating turbulence, trail expansion and break up. The results are unusual since they were obtained in very quiet auroral conditions and at winter highlatitudes, when eddy diffusion from gravity wave breaking is normally weak.

Acknowledgements. This project was funded by NASA grants NNX07AJ99G (Clemson University), NNX07AK02G (Penn State University) and NNX08AC57G (University of Alaska Fairbanks). The missions were professionally executed by NSROC and NASA teams from GSFC Wallops Flight Facility and the staff at Poker Flat Research Range. PFRR is a rocket range operated by the Geophysical Institute of the University Alaska Fairbanks with support 
from NASA. We are grateful for the support from Mike Nicolls and Craig Heinselman for PFISR, Don Hampton, Brian Lawson, and others for instrument support at PFRR and remote sites. Seji Kawamura from NICT provided MF and meteor radar data. The TMA camera sites were operated by Lamar Durham, Brian Turpin, Lucas Hurd, and Patti Larsen from Clemson University. The CONE instruments were manufactured and prepared by Hans-Jürgen Heckl and Boris Strelnikov at IAP. Shelton Simmons helped with the vacuum calibrations at Clemson.

Topical Editor C. Jacobi thanks two anonymous referees for their help in evaluating this paper.

\section{References}

Achatz, U.: Gravity-wave breaking: Linear and primary nonlinear dynamics, Adv. Space Res., 40, 719-733, 2007.

Bishop, R. L., Larsen, M. F., Hecht, J. H., Liu, A. Z., and Gardner, C. S.: TOMEX: Mesospheric and lower thermospheric diffusivities and instability layers, J. Geophys. Res., 109, D02S03, doi:10.1029/2002JD003079, 2004.

Bishop, R. L., Earle, G. D., Larsen, M. F., Swenson, C. M., Carlson, C. G., Roddy, P. A., Fish, C. C., and Bullett, T. W.: Sequential observations of the local neutral wind field structure associated with E region plasma layers, J. Geophys. Res., 110, A04309, doi:10.1029/2004JA010686, 2005.

Blamont, J. E.: Turbulence in the atmospheric motions between 90 and $130 \mathrm{~km}$ of altitude, Planet. Space Sci., 10, 89-101, 1963.

Blamont, J. E. and de Jager, C.: Upper atmospheric turbulence near the $100 \mathrm{~km}$ level, Ann. Geophys., 17, 134-144, 1961.

Collins, R. L. and Smith, R. W.: Evidence of damping and overturning of gravity waves in the arctic mesosphere: Na lidar and $\mathrm{OH}$ temperature observations, J. Atmos. Solar-Terr. Phys., 66, 867-879, 2004.

Collins, R. L., Lehmacher, G. A., Larsen, M. F., and Mizutani, K.: Estimates of vertical eddy diffusivity in the upper mesosphere in the presence of a mesospheric inversion layer, Ann. Geophys., 29, 2019-2029, doi:10.5194/angeo-29-2019-2011, 2011.

Croskey, C. L., Mitchell, J. D., Friedrich, M., Schmidlin, F. J., and Goldberg, R. A.: In-situ electron and ion measurements and observed gravity wave effects in the polar mesosphere during the MaCWAVE program, Ann. Geophys., 24, 1267-1278, doi:10.5194/angeo-24-1267-2006, 2006.

Danilov, A. D., Kalgin, U. A., and Pokhunkov, A. A.: Variation of the turbopause level in the polar regions. Space Research XIX (83), 173-176, 1979.

Giebeler, J., Lübken, F.-J., and Nägele, M.: CONE - a new sensor for in situ observations of neutral and plasma density fluctuations, Proc. 11th ESA Symp. Europ. Rocket Balloon Progr., Montreux, Switzerland, ESA SP-355, 311-318, 1993.

Hall, C. M., Meek, C. E., Manson, A. H., and Nozawa, S.: Turbopause determination, climatology, and climatic trends using medium frequency radars at $52^{\circ} \mathrm{N}$ and $70^{\circ} \mathrm{N}$, J. Geophys. Res., 113, D13104, doi:10.1029/2008JD009938, 2008.

Hecht, J. H., Liu, A. Z., Bishop, R. L., Clemmons, J. H., Gardner, C. S., Larsen, M. F., Roble, R. G., Swenson, G. R., and Walterscheid, R. L.: An overview of observations of unstable layers during the Turbulent Oxygen Mixing Experiment (TOMEX), J. Geophys. Res., 109, D02S01, doi:10.1029/2002JD003123, 2004.
Hillert, W., Lübken, F.-J., and Lehmacher, G.: TOTAL: a rocketborne instrument for high resolution measurements of neutral air turbulence during DYANA, J. Atmos. Terr. Phys., 56, 18351852, 1994.

Ishii, M., Conde, M., Smith, R. W., Krynicki, M., Sagawa, E., and Watari, S.: Vertical wind observations with two Fabry-Perot interferometers at Poker Flat, Alaska, J. Geophys. Res., 106, 10537-10551, 2001.

Larsen, M. F.: Winds and shears in the mesosphere and lower thermosphere: Results from four decades of chemical release wind measurements, J. Geophys. Res., 107, 1215, doi:10.1029/2001JA000218, 2002.

Larsen, M. F. and Fesen, C. G.: Accuracy issues of the existing thermospheric wind models: can we rely on them in seeking solutions to wind-driven problems?, Ann. Geophys., 27, 2277-2284, doi:10.5194/angeo-27-2277-2009, 2009.

Larsen, M. F., Liu, A. Z., Gardner, C. S., Kelley, M. C., Collins, S. C., Friedman, J., and Hecht, J. H.: Observations of overturning in the upper mesosphere and lower thermosphere, J. Geophys. Res., 109, D02S04, doi:10.1029/2002JD003067, 2004.

Lehmacher, G. and Lübken, F.-J.: Simultaneous observation of convective adjustment and turbulence generation by mesospheric gravity wave generation, Geophys. Res. Lett., 22, 2477-2480, 1995.

Lehmacher, G. A., Croskey, C. L., Mitchell, J. D., Friedrich, M., Lübken, F.-J., Rapp, M., Kudeki, E., and Fritts, D. C.: Intense turbulence observed above a mesospheric temperature inversion at equatorial latitude, Geophys. Res. Lett., 33, L08808, doi:10.1029/2005GL024345, 2006.

Lübken, F.-J.: On the extraction of turbulent parameters from atmospheric density measurements, J. Geophys. Res., 97, 2038520395, 1992.

Lübken, F.-J.: Seasonal variation of turbulent energy dissipation rates at high latitudes as determined by in situ measurements of neutral density fluctuations, J. Geophys. Res., 102, 1344113456, 1997.

Lübken, F.-J., Hillert, W., Lehmacher, G., and von Zahn, U.: Experiments revealing small impact of turbulence on the energy budget of the mesosphere and thermosphere, J. Geophys. Res., 98, 20369-20384, 1993.

MacLeod, M. A.: Vertical neutral winds from chemical releases, Proc. 11th Plenary Meeting of COSPAR, Tokyo, 9-21 May 1968, Space Res. IX, 142-150, 1968.

MacLeod, R. and Vincent, R. A.: Observations of winds in the Antarctic summer mesosphere using the spaced antenna technique, J. Atmos. Terr. Phys., 47, 567-574, 1985.

Manney, G. L., Schwartz, M. J., Krüger, K., Santee, M. L., Pawson, S., Lee, J. N., Daffer, W. H., Fuller, R. A., and Livesey, N. J.: Aura Microwave Limb Sounder observations of dynamics and transport during the record-breaking 2009 Arctic stratospheric major warming Geophys. Res. Lett., 36, L12815, doi:10.1029/2009GL038586, 2009.

Nicolls, M. J. and Heinselman, C. J.: Three-dimensional measurements of traveling ionospheric disturbances with the Poker Flat Incoherent Scatter Radar, Geophys. Res. Lett., 34, L21104, doi:10.1029/2007GL031506, 2007.

Offermann, D. Jarisch,, M., Oberheide, J., Gusev, O., Wohltmann, I., Russell III, J. M., and Mlynczak, M. G.: Global wave activity from upper stratosphere to lower thermosphere: A new 
turbopause concept, J. Atmos. Sol. Terr. Phys., 68, 1709-1729, doi:10.1016/j.jastp.2006.01.013, 2006.

Offermann, D., Jarisch, M., Schmidt, H., Oberheide, J., Grossmann, K.-U., Gusev, O., Russell III, J. M., and Mlynczak, M. G.: The "wave turbopause", J. Atmos. Sol. Terr. Phys., 69, 2139-2158, doi:10.1016/j.jastp.2007.05.012, 2007.

Offermann, D., Gusev, O., Donner, M., Forbes, J. M., Hagan, M., Mlynczak, M. G., Oberheide, J., Preusse, P., Schmidt, H., and Russell III, J. M.: Relative intensities of middle atmosphere waves, J. Geophys. Res., 114, D06110, doi:10.1029/2008JD010662, 2009.

Philbrick, C. R., Schmidlin, F. J., Grossmann, K. U., Lange, G., Offermann, D., Baker, K. D., Krankowsky, D., and von Zahn, U.: Density and temperature structure over northern Europe, J. Atmos. Terr. Phys., 47, 159-172, 1985.

Picone, J. M., Hedin, A. E., Drob, D. P., and Aikin, A. C.: NRLMSISE-00 empirical model of the atmosphere: Statistical comparisons and scientific issues, J. Geophys. Res., 107, 1468, doi:10.1029/2002JA009430, 2002.

Rapp, M., Gumbel, J., and Lübken, F.-J.: Absolute density measurements in the middle atmosphere, Ann. Geophys., 19, 571-580, doi:10.5194/angeo-19-571-2001, 2001.

Rees, D.: Vertical winds in the lower ionosphere, J. British Interplanetary Society, 22, 275-284, 1969.
Rees, D., Roper, R. G., Lloyd, K. H., and Low, C. H.: Determination of the structure of the atmosphere between 90 and $250 \mathrm{~km}$ by means of contaminant releases at Woomera, May 1968, Philos. Trans. R. Soc. London, Ser. A, 271, 631-663, 1972.

Roper, R. G.: Rocket vapor trail releases revisited: Turbulence and the scale of gravity waves: Implications for the imaging Doppler interferometry/incoherent scatter radar controversy, J. Geophys. Res., 101, 7013-7017, 1996.

Thurairajah, B., Collins, R. L., Harvey, V. L., Lieberman, R. S., Gerding, M., Mizutani, K., and Livingston, J. M.: Gravity wave activity in the Arctic stratosphere and mesosphere during the 2007-2008 and 2008-2009 stratospheric sudden warming events, J. Geophys. Res., 115, D00N06, doi:10.1029/2010JD014125, 2010.

von Zahn, U., Lübken, F.-J., and Pütz, C.: BUGATTI Experiments: Mass spectrometric studies of lower thermosphere eddy mixing and turbulence, J. Geophys. Res., 95, 7443-7465, 1990.

Weinstock, J.: Energy dissipation rates of turbulence in the stable free atmosphere, J. Atmos. Sci., 38, 880-883, 1981.

Wescott, E. M., Stenbaek-Nielsen, H., Conde, M., Larsen, M. F., and Lummerzheim, D.: The HEX experiment: Determination of the neutral wind field from 120 to $185 \mathrm{~km}$ altitude near a stable premidnight auroral arc by triangulating the drift of rocket-deployed chemical trails, J. Geophys. Res., 111, A09302, doi.10.1029/2005JA011002, 2006. 